NBER WORKING PAPER SERIES

MEASURING BUSINESS CYCLES: A MODERN PERSPECTIVE

Francis X. Diebold

Glenn D. Rudebusch

Working Paper No. 4643

\author{
NATIONAL BUREAU OF ECONOMIC RESEARCH \\ 1050 Massachusetts Avenue \\ Cambridge, MA 02138 \\ February 1994
}

This paper was prepared for the NBER Economic Fluctuations Conference on Developments in Business Cycle Research, October 22-23, 1993, Cambridge, MA. We thank Alan

Auerbach, Antúlio Bomfim, Russell Cooper, Steve Durlauf, Jim Hamilton, Jim Stock, and Mark Watson for their constructive comments. We thank the National Science Foundation, the Sloan Foundation, and the University of Pennsylvania Research Foundation for support. The hospitality of the University of Chicago, where parts of this work were completed, is gratefully acknowledged. We are also grateful to Jose Lopez and Marcelle Chauvet, who provided assistance with many of the computations. The views expressed here are not necessarily those of the Board of Governors of the Federal Reserve System or its staff, or of the National Bureau of Economic Research. This paper is part of NBER's research program in Economic Fluctuations. 


\title{
MEASURING BUSINESS CXCLES: A MODERN PERSPECTIVE
}

\begin{abstract}
In the first half of this century, special attention was given to two features of the business cycle: (1) the comovement of many individual economic series and (2) the different behavior of the economy during expansions and contractions. Both of these attributes were ignored in many subsequent business cycle models, which were often linear representations of a single macroeconomic aggregate. However, recent theoretical and empirical research has revived interest in each attribute separately. Notably, dynamic factor models have been used to obtain a single common factor from a set of macroeconomic variables, and nonlinear models have been used to describe the regime-switching nature of aggregate output. We survey these two strands of research and then provide some suggestive empirical analysis in an effort to unite the two literatures and to assess their usefulness in a statistical characterization of business-cycle dynamics.
\end{abstract}

Francis X. Diebold

Department of Economics 3718 Locust Walk

University of Pennsylvania

Philadelphia, PA 19104-6297
Glenn D. Rudebusch

Federal Reserve Board

20th and Constitution Avenue, NW Washington, D.C. 20551 


\section{Introduction}

It is desirable to know the facts before attempting to explain them; hence, the attractiveness of organizing business-cycle regularities within a model-free framework.

During the first half of this century, much research was devoted to obtaining just such an empirical characterization of the business cycle. The most prominent example of this work was Burns and Mitchell (1946), whose summary empirical definition was:

Business cycles are a type of fluctuation found in the aggregate economic activity of nations that organize their work mainly in business enterprises: a cycle consists of expansions occurring at about the same time in many economic activities, followed by similarly general recessions, contractions, and revivals which merge into the expansion phase of the next cycle.

(p. 3)

Burns and Mitchell's definition of business cycles has two key features. The first is the comovement among individual economic variables. Indeed, the comovement among series, taking into account possible leads and lags in timing, was the centerpiece of Burns and Mitchell's methodology. In their analysis, Burns and Mitchell considered the historical concordance of hundreds of series, including those measuring commodity output, income, prices, interest rates, banking transactions, and transportation services. They used the clusters of turning points in these individual series to determine the monthly dates of the turning points in the overall business cycle.' Similarly, the early emphasis on the consistent pattern of comovement among various variables over the business cycle led directly to the creation of composite leading, coincident, and lagging indexes (e.g., Shishkin, 1961).

The second prominent element of Burns and Mitchell's definition of business cycles is their division of business cycles into separate phases or regimes. Their analysis, as was typical at the time, treats expansions separately from contractions. For example, certain series are classified as leading or lagging indicators of the cycle, depending on the general state of

1 See Diebold and Rudebusch (1992) for further discussion of the role of comovement in determining business-cycle turning points. 
business conditions.

Both of the features highlighted by Burns and Mitchell as key attributes of business cycles were less emphasized in postwar business-cycle models--particularly in empirical models where the focus was on the time series properties of the cycle. Most subsequent econometric work on business cycles followed Tinbergen (1939) in using the linear difference equation as the instrument of analysis. This empirical work has generally focused on the time-series properties of just one or a few macroeconomic aggregates, ignoring the pervasive comovement stressed by Bums and Mitchell. Likewise, the linear structure imposed eliminated consideration of any nonlinearity of business cycles that would require separate analyses of expansions and contractions.

Recently, however, empirical research has revived consideration of each of the attributes highlighted by Bums and Mitchell. Notably, Stock and Watson (1989, 1991, 1993) have used a dynamic factor model to capture comovement by obtaining a single common factor from a set of many macroeconomic series, and Hamilton (1989) has estimated a nonlinear model for real GNP with discrete regime switching between periods of expansion and contraction.

This paper is part survey, part interpretation, and part new contribution. We describe the dynamic-factor and regime-switching models in some detail in sections II and III, and we sketch their links to recent developments in macroeconomics in section IV. The modern dynamic-factor and regime-switching literatures, however, have generally considered the comovement and regime-switching aspects of the business cycle in isolation of each other. Thus, in section $V$, we attempt at an empirical synthesis in a comprehensive framework that admits the possibility of both factor structure and regime switching. We conclude in section VI. 


\section{Comovement: Factor Structure}

In a famous essay, Lucas (1976) drew attention to a key business-cycle fact: outputs of broadly-defined sectors move together. Lucas' view is part of a long tradition that has stressed the coordination of activity among various economic actors and the resulting comovement in sectoral outputs. In this section, we focus on a modern dynamic model that captures such comovement.

Analysis of comovement in dynamic settings typically makes use of two nonparametric tools, the autocorrelation function and the spectral density function. In the time domain, one examines multivariate dynamics via the autocorrelation function, which gives the correlations of each variable with its own past and with the past of all other variables in the system. Such analyses are now done routinely, as in Backus and Kehoe (1992), who characterize the dynamics of output, consumption, investment, government purchases, net exports, money, and prices across ten countries and a hundred years.

Alternatively, one examines dynamics in the frequency domain via the spectral density function, the Fourier transform of the autocovariance function, which presents the same dynamic information but in a complementary fashion. The spectral density matrix decomposes variation and covariation among variables by frequency, permitting one to concentrate on the dynamics of interest (business-cycle dynamics, for example, correspond to periods of roughly 2-8 years). Transformations of both the real and imaginary parts of the spectral density matrix have immediate interpretation in business-cycle analysis; the coherence between any two economic time series effectively charts the strength of their correlation by frequency, while the phase charts lead/lag relationships by frequency. A good example of business-cycle analysis in the frequency domain is Sargent (1987), who examines the spectral density matrix of seven U.S. data series: real GNP, the unemployment rate, the interest rate. 
the change in real money stock, inflation, productivity, and real wages. ${ }^{2}$

Of course, one can analyze business-cycle data parametrically as well, by approximating the dynamic relationships with a particular statistical model. In this regard, the vector autoregression, introduced by Sims (1980), is ubiquitous. The moving-average representation (that is, the impulse-response function) of a vector autoregression of a set of macroeconomic variables provides a readily-interpretable characterization of dynamics, by charting the response of each variable to shocks in the other variables.

Unfortunately, a vector-autoregressive study that attempts to capture the pervasive comovement among hundreds of series emphasized by Burns and Mitchell requires more degrees of freedom than are available in macroeconomic samples. However, recent work provides crucial dimensionality reduction because the dynamic comovements among large sets of macroeconomic variables can often be well described by a particular configuration of the vector autoregression associated with index structure, or factor structure.

Factor models have a long history of use in cross-sectional settings, and their generalization to dynamic environments is due to Sargent and Sims (1977), Geweke (1977) and Watson and Engle (1983). Important recent contributions include Stock and Watson (1989, 1991, 1993) and Quah and Sargent (1993), among others. The idea is simply that the comovement of contemporaneous economic variables may be due to the fact that they are driven, at least in part, by common shocks. Thus, the behavior of the set of $\mathrm{N}$ variables is qualitatively similar to the behavior of just one variable, the common factor. This allows parsimonious modeling while nevertheless maintaining fidelity to the notion of pervasive

\footnotetext{
${ }^{2}$ In the frequency domain, Sargent (1987, p. 282) offers the following update of Burns and Mitchell's definition: ". . the business cycle is the phenomenon of a number of important economic aggregates (such as GNP, unemployment, and layoffs) being characterized by high pairwise coherences at the low business cycle frequencies."
} 
macroeconomic comovement. ${ }^{3}$

Let us focus on the dynamic factor model of Stock and Watson (1991), which was developed as a modern statistical framework for computing a composite index of coincident indicators. In their one-factor model, movements in the $\mathrm{N}$ macroeconomic variables of interest, $\left\{x_{1}\right\}$, are determined by changes in the one-dimensional unobserved common factor, $f_{t}$, and by the $\mathrm{N}$-dimensional idiosyncratic component, $u_{\mathrm{i}}$ :

$$
\begin{array}{rl}
x_{t} & =\beta+\lambda f_{t}+u_{t} \\
N x 1 & N x 1+N x 11 \times 1 N x 1
\end{array}
$$

$D(L) u_{t}=e_{t}$ $\mathrm{NxN} \mathrm{Nx} 1 \mathrm{Nx} 1$

$$
\begin{aligned}
& \phi(L)\left(f_{1}-\delta\right)=\eta_{\ell} . \\
& |x| \quad|x| 1 \times 1
\end{aligned}
$$

All idiosyncratic stochastic dynamics are driven by $\varepsilon$, while all common stochastic dynamics, which are embodied in the common factor, are driven by $\eta_{t}$. Following Stock and Watson, identification is achieved by assuming that $\left(u_{1 t}, \ldots, u_{N t}, f_{1}\right\}$ are orthogonal at all leads and lags, which is achieved by making $D(L)$ diagonal and $\left\{\varepsilon_{1 t}, \ldots, \varepsilon_{\mathrm{N} t}, \eta_{t}\right\}$ orthogonal at all leads and lags, and by setting the scale of the factor by imposing $\operatorname{var}\left(\eta_{1}=1\right)$.

The idea of common shocks permeates dynamic econometrics. Besides the dynamic factor setup, a number of other econometric tools are also intimately connected to the idea of shock commonality. For example, the Engle-Granger (1987) cointegration concept fits

\footnotetext{
${ }^{3}$ It is interesting to note that parallel structures may to exist in many financial markets, which makes sense to the extent that asset prices accurately reflect fundamentals. See Singleton (1980), Bollerslev, Engle and Wooldridge (1988), and Diebold and Nerlove (1989), among others, for examples of factor structure in both the conditional means and conditional variances of various asset retums.
} 
precisely into the common-factor setup. The key feature of a cointegrated system is that although all variables in the system are integrated, there are fewer unit roots than variables. It is the common underlying unit roots in cointegrated systems--characterized formally in the "common trends" representation of Stock and Watson (1988)--that links cointegration to the idea of common factors. Furthermore, the recent idea of common features, introduced by Engle and Kozicki (1993), is a direct generalization of cointegration and is therefore intimately connected to factor structure as well.

\section{Nonlinearity: Regime Switching}

Underlying much of the traditional business cycle literature is the notion that a good statistical characterization of business-cycle dynamics may require some notion of regime switching between "good" and "bad" states." Models incorporating regime switching have a long tradition in dynamic econometrics. ${ }^{3}$ One recent time-series model squarely in line with the regime-switching tradition is the "threshold" model (e.g., Tong, 1983; Potter, 1992). In a threshold model, the regime switches according to the observable past history of the system. While the threshold approach is of interest, it may be more appropriate for our purposes to use a model in which the state is latent, rather than observable. The recent work of Hamilton $(1989,1990,1993)$ achieves just that. In Hamilton's regime-switching model, time-series dynamics are governed by a finite-dimensional parameter vector that switches (potentially each period) depending upon which of two unobservable states is realized, with state transitions governed by a first-order Markov process.

\footnotetext{
4 Again, parallel structures may exist in financial markets. Regime switching has been found in the conditional mean dynamics of interest rates (Hamilton, 1988; Cecchetti, Lam and Mark, 1990) and exchange rates (Engel and Hamilton, 1990), and in the conditional variance dynamics of stock returns (Hamilton and Susmel, 1992).

${ }^{5}$ Key early contributions include the early work of Quandt (1958) and Goldfeld and Quandt (1973).
} 
Economic considerations suggest the potential desirability of allowing the transition probabilities associated with the Markov process to vary through time. For example, in the context of business-cycle dynamics, it is plausible that the likelihood of a turning point depends upon the duration-to-date of the current regime (expansion or contraction); certainly, one would not want to exclude that possibility from the outset. For this reason, we shall sketch a version of Hamilton's model that allows for time-varying transition probabilities, due to Diebold, Lee and Weinbach (1993) and Filardo (1993).

Let $\left\{s_{1}\right\}_{i=1}^{\mathrm{T}}$ be the sample path of a latent first-order, two-state Markov process, taking values 0 or 1, with transition probability matrix illustrated in Figure 1. As is apparent from the figure, the two transition probabilities are potentially time-varying, evolving as logistic functions of $x_{t-1}^{\prime} \beta_{1}, i=0,1$, where the conditioning vector $x_{t-1}$ contains variables that affect the state transition probabilities. When all but the first elements of the $\beta$ vectors are set to zero, the transition probabilities are constant.

Now let $\left(y_{1}\right\}_{t=1}^{T}$ be the sample path of a time series that depends on $\left\{s_{t}\right\}_{t=1}^{T}$ such that the density of $y_{t}$ conditional upon $s_{t}$ is

$$
f\left(y_{t} \mid s_{t} ; \theta\right)=\frac{1}{\sqrt{2 \pi} \sigma} \exp \left(\frac{-\left(y_{1}-\mu_{s}\right)^{2}}{2 \sigma^{2}}\right) .
$$

Thus, $y_{1}$ is white noise with a potentially switching mean. The two means around which $y_{1}$ moves are of particular interest and may, for example, correspond to episodes of differing growth rates ("expansions" and "contractions").

The central idea of regime switching is simply that expansions and contractions may be usefully treated as different probabilistic objects. This idea has been an essential part of the Burns-Mitchell-NBER tradition of business-cycle analysis and is also manifest in the great interest in the popular press, for example, in identifying and predicting turning points in economic activity. Yet it is only within a regime-switching framework that the concept of a 
turning point has intrinsic meaning. Recent contributions that have emphasized the use of probabilistic models in the construction and evaluation of turning-point forecasts and chronologies include Neftci (1982) and Diebold and Rudebusch (1989).

Numerous recent contributions revolve around the basic switching model, implicitly or explicitly. For example, Neftci's (1984) well-known analysis of business-cycle asymmetry amounts to asking whether the Markov transition probability matrix (assumed to be constant) is symmetric. Similarly, analyses of business-cycle duration dependence amount to asking whether the transition probabilities are constant. Diebold and Rudebusch (1990), Filardo (1993), and Diebold, Rudebusch and Sichel (1993) have found positive duration dependence in postwar U.S. contractions; that is, the longer a contraction persists, the more likely it is to end. This confirms the desirability of allowing the transition probabilities in Markov regimeswitching models to vary. Similar results have been obtained by Durland and McCurdy (1992) using the technology of semi-Markov processes.

Other forms of time-varying transition probabilities may be important as well. Ghysels (1993a, b), in particular, argues that business-cycle state transition probabilities vary seasonally and provides formal methods for analyzing such variation. General models of time-varying hazard rates (transition probabilities) have also been studied recently by De Toldi, Gourieroux and Monfort (1992).

Finally, the possibility of more than two states may of course be entertained. Sichel (1992), for example, provides some evidence of a third state in business-cycle dynamics. Sichel's third state is a "recovery" period at the beginning of expansions, corresponding to much faster than usual expansionary growth. Potter (1992) produces evidence that leads to a similar view. 


\section{Factor Structure and Regime Switching: Links to Macroeconomic Theory}

In this section, as further motivation, we describe some of the links between macroeconomic theory and factor structure and regime switching. We use convex equilibrium business-cycle models to motivate the appearance of factor structure and non-convex models with multiple equilibria to motivate regime switching; however, we hasten to add that these pairings are by no means exclusive. Moreover, of course, our ultimate interest lies in models that simultaneously display factor structure and regime-switching behavior, which as the following discussion suggests might occur in a variety of ways.

\section{A. Macroeconomic Theory and Factor Structure}

The econometric tradition of comovement through factor structure is consistent with a variety of modern dynamic macroeconomic models. Here we highlight just one--a linearquadratic equilibrium model--in order to motivate the appearance of factor structure. We follow the basic setup of Hansen and Sargent (1993), which although arguably rigid in some respects, has two very convenient properties. First, the discounted dynamic programming problem associated with the model may be solved easily and exactly. Second, the equilibria of such models are precisely linear (that is, precisely a vector autoregression), thereby bringing theory into close contact with econometrics.

Assume preferences are quadratic and are defined over consumption of services, $s_{b}$, and work effort, $l_{1}$, with shocks $b_{1}$ determining a stochastic bliss point. There are four linear constraints on the utility maximization. The first specifies that a weighted average of the output of consumption goods, $c_{p}$ intermediate goods, $g_{k}$, and investment goods, $i_{b}$, equals a linear combination of lagged capital stock, $k_{t-1}$, and work effort, plus the technology shock, $d_{1}$. The second is the law of motion for the capital stock: Capital accumulates through additional investment minus depreciation. The third is the law of motion for "household capital," $h_{b}$, which is driven by consumption expenditures. The last constraint specifies that consumption 
services today depend on lagged household capital and current consumption. The planning problem associated with this model is

$$
\max -\frac{1}{2} E \sum_{t=0}^{\infty} \beta^{1}\left[\left(s_{t}-b_{t}\right) \cdot\left(s_{t}-b_{t}\right)+1_{t}^{2}\right]
$$

subject to the four constraints ${ }^{6}$

$$
\begin{gathered}
\alpha_{1} c_{1}+\alpha_{2} g_{t}+\alpha_{3} i_{1}=\alpha_{4} k_{t-1}+\alpha_{5} l_{t}+d_{t} \\
k_{t}=\beta_{1} k_{t-1}+\beta_{2} i_{t} \\
h_{t}=\gamma_{1} h_{t-1}+\gamma_{2} c_{t} \\
s_{t}=\delta_{1} h_{t-1}+\delta_{2} c_{t} .
\end{gathered}
$$

The exogenous uncertainty in the model evolves according to

$$
z_{i+1}=\rho_{1} z_{1}+\rho_{2} w_{1+1}
$$

and the preference and technology shocks $\left(b_{1}\right.$ and $\left.d_{1}\right)$ are linear transformations of the $z_{1}$,

$$
\mathrm{b}_{\mathrm{i}}=\mathrm{U}_{\mathrm{b}} \mathrm{z}_{\mathrm{b}}, \mathrm{d}_{\mathrm{i}}=\mathrm{U}_{\mathrm{d}} \mathrm{z}_{\mathrm{i}}
$$

Most importantly for our purposes, note that this framework can potentially describe the determination of a large set of series. All variables (except $\mathcal{L}$ ) can be considered as vectors of different goods or services with the parameters interpreted as conformable matrices.

The equilibrium of this economy is a linear stochastic process and can be represented by a vector autoregression constrained by cross-equation restrictions. Most importantly, this vector autoregression will have factor structure so long as the number of shocks is less than the number of variables in the system. The equilibrium has state space form

${ }^{6}$ Consumption appears in both of the last two equations in order to capture both its durable and nondurable aspects. 


$$
\begin{gathered}
x_{t+1}=A x_{t}+C w_{t+1} \\
y_{t}=G x_{t},
\end{gathered}
$$

where the state vector $x_{t}$ contains $h_{t}, k_{t}$, and $z_{t}$, and $y_{t}$ can contain any variable that can be expressed as a linear function of the state variables. The Kalman filter can be used with the model in state space form to obtain the innovations and hence construct the Gaussian likelihood.

Fewer shocks than observables is the rule, not the exception. The standard setups have just a few preference and technology shocks driving a comparatively large number of decision variables, thereby building in factor structure. In fact, in the leading case of a single technology shock and no preference shocks, one shock is responsible for all variation in the choice variables, resulting in an equilibrium that maps into a special (singular) case of the one-factor model discussed earlier. In that special case, there are no idiosyncratic shocks (or equivalently, they have zero variance).

To reconcile the singular equilibrium from the model economy with the clearly nonsingular nature of the data, measurement error is often introduced.' The state-space representation becomes

$$
\begin{aligned}
x_{t+1} & =A x_{t}+C w_{t+1} \\
y_{1} & =G x_{t}+v_{t},
\end{aligned}
$$

where $v_{t}$ is a martingale difference sequence. In single-shock linear-quadratic models with measurement error, the equilibria are precisely of the single-factor form, with non-degenerate idiosyncratic effects.

Feeling constrained by linear technology and quadratic preferences, many authors have recently focused on models that are not linear-quadratic. See, for example, Kydland and

\footnotetext{
${ }^{7}$ See Sargent (1989), and Hansen and Sargent (1993), among others.
} 
Prescott (1982), Hansen (1985), Cooley and Hansen (1990), and Cooley (1993). The formulation is basically the same as in the linear-quadratic case, but the mechanics are more complicated. The discounted dynamic programming problem associated with the recursive competitive equilibrium can only be solved approximately; however, the decision rules are nevertheless well-approximated linearly near the steady state. Under regularity conditions, the equilibrium is a Markov process in the state variables, and if that Markov process converges to an invariant distribution, then a vector-autoregressive representation exists. Again, the vector autoregression is only an approximation to the generally nonlinear decision sules, and its computation can be tedious. However, the availability of a factor structure for modelling this approximation remains.

\section{B. Macroeconomic Theory and Regime Switching}

Regime-switching behavior is also consistent with a variety of macroeconomic models. Here we focus on models with coordination failures, which produce multiple equilibria. In what follows, we shall provide a brief overview of this theoretical literature and its relation to the regime-switching model.

Much has been made of the role of spillovers and strategic complementarities in macroeconomics (Cooper and John, 1988). "Spillover" simply refers to a situation in which others' strategies affect one's own payoff. "Strategic complementarity" refers to a situation in which others' strategies affect one's own optimal strategy. Spillovers and strategic complementarities arise, for example, in models of optimal search (e.g., Diamond, 1982), where thick-market externalities ensure that the likelihood of successful search depends on the intensity of search undertaken by others, which in turn affects one's own optimal search intensity. In short, search is more desirable when other agents are also searching, because it is likely to be more productive.

Spillovers and strategic complementarities may have important macroeconomic effects. 
For example, the appearance of aggregate increasing returns to scale (e.g., Hall, 1989) may simply be an artifact of the positive externalities associated with high output levels in the presence of spillovers and strategic complementarities rather than true increasing returns in firms' technologies. Indeed, Caballero and Lyons (1992) find little evidence of increasing returns at the individual level, yet substantial evidence at the aggregate level, suggesting the importance of spillovers and strategic complementarities.

Spillovers and strategic complementarities can produce multiple equilibria, the dynamics of which may be well-approximated by statistical models involving regime switching. ${ }^{8}$ In fact, Cooper and John (1988) stress the existence of multiple equilibria, with no coordination mechanism, as a common theme in a variety of seemingly-unrelated models displaying spillovers and strategic complementarities. Moreover, the equilibria are frequently Pareto-rankable. Situations arise, for example, in which an economy is in a low-output equilibrium such that all agents would be better off at higher output levels, but there is no coordination device to facilitate the change.

Most work on coordination failures fails to deliver a mechanism for endogenizing switches between equilibria, although some very recent work is progressing in that direction. One approach involves variations on Keynesian "animal spirits," or self-fulfilling waves of optimism and pessimism, as formalized by Azariadis (1981) and Cass and Shell (1983). Notably, Diamond and Fudenberg (1989) demonstrate in a search framework the existence of rational-expectations sunspot equilibria in which agents' beliefs about cycles are selffulfilling. Howit and McAfee (1992) obtain results even more in line with our thesis in a model in which waves of optimism and pessimism evolve according to a Markov process. The statistical properties of equilibria from their model are well-characterized by a Markov

\footnotetext{
${ }^{8}$ Durlauf (1991) and Cooper and Durlauf (1993) provide insightful discussion of this point.
} 
regime-switching process. ${ }^{9}$

Finally, Cooper (1993) proposes a history-dependent selection criterion in an economy with multiple Nash equilibria corresponding to different levels of productivity. The Cooper criterion reflects the idea that history may create a focal point: a person's recent experience is likely to influence her expectations of others' future strategic behavior, resulting in a slow evolution of conjectures about others' actions. Cooper's analysis highlights the importance of learning to respond optimally to the strategic actions of others. The Cooper criterion leads to persistence in the equilibrium selected, with switching occurring as a consequence of large shocks, phenomena which again may be well-characterized by statistical models involving regime switching.

\section{Synthesis: Regime Switching in a Dynamic Factor Model}

We have argued above that both comovement through factor structure and nonlinearity through regime switching are important elements to be considered in an analysis of business cycles. It is unfortunate, therefore, that the two have recently been considered largely in isolation from each other. In what follows, we sketch a framework for the analysis of business-cycle data that incorporates both factor structure and regime switching in a natural way. We believe that this framework, although not formally utilized before, may be a good approximation to the one implicitly adopted by many scholars of the cycle.

\section{A. A Model}

We propose a dynamic factor model in which the factor switches regimes. First consider a switching model for the factor $f_{\mathfrak{t}}$; we work with a slightly richer regime-switching model than before. Again let $\left\{s_{t}\right\}_{t=1}^{\top}$ be the sample path of a latent first-order two-state

\footnotetext{
${ }^{9}$ Related approaches have been proposed by Durlauf (1994) and Evans and Honkapohja (1993), among others.
} 
Markov process (taking on values 0 and 1 ) with the potentially time-varying transition probability matrix illustrated in Figure 1 , let $\left\{f_{t}\right\}_{\text {tel }}^{T}$ be the sample path of the factor (which depends on $\left.\left(s_{t}\right\}_{(=1}^{\mathrm{T}}\right)$, and collect the relevant history of the factor and state in the vector $z_{t}=\left(s_{t}, s_{t-1}, \ldots, s_{t-p}, f_{t-1}, \ldots, f_{t-p}\right)^{\prime}$. We postulate that the probabilistic dependence of $f_{f}$ on $z_{i}$ is summarized by the conditional density

$$
P\left(f_{i} \mid z_{i} ; \theta\right)=\frac{1}{\sqrt{2 \pi} \sigma} \exp \frac{-\left(\left(f_{i}-\mu_{s}\right)-\sum_{i=1}^{p} \phi_{i}\left(f_{t-1}-\mu_{s_{n-1}}\right)\right)^{2}}{2 \sigma^{2}} .
$$

The latent factor, then, follows a pth-order Gaussian autoregression with potentially changing mean. ${ }^{10}$ The two means around which the factor moves are of particular interest; call them $\mu_{1}$ (slow growth) and $\mu_{2}$ (fast growth).

Now let us build the rest of the model around the regime-switching factor. We write

$$
\Delta x_{t}=\beta+\lambda f_{t}+u_{t}
$$

$\mathrm{Nx} 1 \mathrm{Nx} 1 \mathrm{Nx} 1 \mathrm{~lx} 1 \mathrm{Nx} 1$

\section{$D(L) u_{t}=\varepsilon_{1}$ \\ $\mathrm{NxN} \mathrm{Nxl} \mathrm{Nxl}$}

where $\left\{f_{v}, s_{t}\right\}$ follows the regime-switching process detailed above. To identify the model, we assume that $\left\{u_{\mathrm{te}}, \ldots, u_{\mathrm{Ne}}, f_{\mathrm{l}}\right\}$ are orthogonal at all leads and lags, which is achieved by making $D(L)$ diagonal and $\left\{\varepsilon_{10}, \ldots, \varepsilon_{N e} \cdot \eta_{\mathrm{l}}\right\}$ orthogonal at all leads and lags. So as not to interfere with the possible regime switching in the variance of $\eta_{t}$, however, we discard the earlier normalization on $\eta_{\mathrm{s}}$ in favor of a normalization on one of the factor loadings

${ }^{10}$ For notational purposes, we shall continue to refer to the innovation driving the factor as $\eta_{i}$. That is, $\eta_{t}=\left(f_{t}-\mu_{s}\right)-\sum_{i=1}^{p} \phi_{i}\left(f_{t-1}-\mu_{s_{m}}\right)$. 
$\left(\lambda_{1}=1\right.$, say $) .{ }^{11}$

\section{B. A Look at the Data}

Let us first describe the data. We examine quarterly economic indicators, 1952.I 1993.I, as described in detail in Table 1. The data include three composite indexes of coincident indicators, corresponding to three alternative methodologies: Commerce Department, modified Commerce Department, and Stock-Watson. The component indicators underlying the Commerce Department and modified Commerce Department indexes are identical (personal income less transfer payments, index of industrial production, manufacturing and trade sales, and employees on non-agricultural payrolls); only their processing differs slightly (see Green and Beckman, 1992). The Stock-Watson index introduces a change in the list of underlying indicators (employees on nonagricultural payrolls is replaced by hours of employees on nonagricultural payrolls) and of course processes the underlying component indicators differently than either the Commerce Department or modified Commerce Department indexes. We obtained qualitatively similar results from all of the indexes; thus, we shall focus here on the Commerce Department's modified Composite Coincident Index. Henceforth, we shall refer to it simply as the "Composite Coincident Index."

We graph the $\log$ of the Composite Coincident Index in Figure 2. It tracks the business cycle well, with obvious and pronounced drops corresponding to the NBERdesignated recessions of $1958,1960,1970,1974,1980,1982$ and 1990 . We similarly graph

"Numerous variations on the identifying restrictions suggested here may of course be entertained; in any case, the identifying assumptions are not used in the preliminary empirical work below, because we do not estimate the full model. 
the logs of the four components of the Composite Coincident Index in figure $3 .^{12}$ Their behavior closely follows that of the Composite Coincident Index.

We shall not provide maximum-likelihood estimates (or any other estimates) of a fully-specified dynamic-factor model with regime-switching factor. To do so would be overly ambitious for a broad survey like this one. Instead, we shall sift the data in two simple exercises to provide suggestive evidence as to whether the data accord with our basic thesis.

First, we work directly with the Composite Coincident Index, which is essentially an estimate of the common factor underlying aggregate economic activity. ${ }^{13}$ We ask whether its dynamics are well-approximated by a switching model. We fit a Markov-switching model to one hundred times the change in the natural logarithm of the Composite Coincident Index, with one autoregressive lag and a potentially switching mean. The results appear in the second column of Table $2 .^{14}$

A notable feature of the results is the high level of statistical significance of the regime switching, which requires some elaboration. The vast majority of the dozens of papers fitting Markov switching models make no attempt to test the null hypothesis of one state against the alternative of two. ${ }^{15}$ This is because the econometrics of testing for regime switching are nonstandard. Hansen $(1991,1992)$ points out that the transition probabilities are not identified under the one-state null, and moreover, that the score with respect to the mean parameter of interest is identically zero if the probability of staying in state 1 is either 0 or 1. In either event, the information matrix is singular. Hansen proposes a bounds test that

${ }^{12}$ Each of the four component indicators is graphed on a different scale to enable their presentation in one graph. For this reason, no scale appears on the vertical axis of the graph.

${ }^{13}$ Stock and Watson motivate and derive their index in precisely this way. The Commerce indexes are attempts at the same methodology, albeit less formally.

${ }^{14}$ We give the startup values for iteration in the first column of Table 2.

${ }^{15}$ See Hamilton's (1993) survey, and the many papers cited there. 
is valid in spite of these difficulties, but its computational difficulty has limited its applicability.

A closely related approach is operational, however. The key is to treat the transition probabilities as nuisance parameters (ruling out from the start the problematic boundary values 0 and 1) and to exploit another of Hansen's $(1991,1992)$ result that the likelihood ratio test statistic for the null hypothesis of one state is the supremum over all admissible values of the nuisance parameters (the transition probabilities). Formally, let

$$
L R=2\left[\ln L\left(\hat{\theta}, \hat{\mathbf{p}}^{11}, \hat{\beta}^{22}\right)-\ln L(\hat{\theta})\right]
$$

and

$$
\operatorname{LR}\left(\mathrm{p}^{11}, \mathrm{p}^{22}\right)=2\left[\ln \mathrm{L}\left(\theta\left(\mathrm{p}^{11}, \mathrm{p}^{22}\right), \mathrm{p}^{11}, \mathrm{p}^{22}\right)-\ln \mathrm{L}(\hat{\theta})\right]
$$

where

$$
\ln L\left(\theta, \mathrm{p}^{11}, \mathrm{p}^{22}\right)=\ln \mathrm{P}\left(\mathrm{y}_{1}, \ldots, \mathrm{y}_{\mathrm{r}} \text { heta, } \mathrm{p}^{11}, \mathrm{p}^{22}\right)
$$

with $\theta=\left(\mu_{1}, \mu_{2}, \sigma^{2}\right)^{\prime}$. Then

$$
L R=\sup ^{11}, p^{2{ }^{2} \in(0,1)} \operatorname{LR}\left(\mathrm{p}^{11}, \mathrm{p}^{22}\right)
$$

The asymptotic distribution of LR has been tabulated by Garcia (1992) for the AR(1) case and shown to be highly accurate in samples of our size. ${ }^{16}$ The critical values depend on the value of the autoregressive parameter, but in no case is the $1 \%$ critical value greater than twelve. Our test statistic is much larger than twelve.

${ }^{16}$ This makes clear the intimate connection of this testing problem to Andrews' (1993) test of structural change with breakpoint identified from the data. Therefore the results of Gine and Zinn (1990) and Stinchcombe and White (1993), used by Diebold and Chen (1993) use to argue the validity of the bootstrap in Andrews' case, are relevant here as well. We shall not pursue the bootstrap here, however. 
Several other aspects of the results are notable. First, the state- 0 mean is significantly negative, and the state-1 mean is significantly positive, and the magnitudes of the estimates accord with our priors. Second, the within-state dynamics display substantial persistence. Third, the estimated staying probabilities accord with the well-known fact that expansion durations are longer than contraction durations on average. Finally, we graph in Figure 4 the time series of smoothed (that is, conditional upon all observations in the sample) probabilities that the Composite Coincident Index was in state 0; the smoothed state- 0 probabilities are in striking accord with the professional consensus as to the history of U.S. business cycles. ${ }^{17}$

In our second exercise, we fit switching models to the individual indicators underlying the Composite Coincident Index and examine the switch times for commonality. In a similar fashion to our analysis of the Composite Coincident Index, we fit models to one hundred times the change in the natural logarithm of each of the underlying coincident indicators, with one autoregressive lag and potentially switching means.

The results appear in columns three through six of Table $2 .{ }^{18}$ The component-bycomponent results are qualitatively similar to those for the Composite Coincident Index, as would be expected in the presence of a regime-switching common factor. Further evidence in support of factor structure emerges in Figure 5, in which we graph the time series of smoothed state- 0 probabilities for each of the four component coincident indicators. There is commonality in switch times, which again is indicative of factor structure. Note, however, that the evidence of switching in the individual series is generally weaker than the evidence of switching in the index. This is consistent with the our switching-factor argument. Individual series are swamped my measurement error, but moving to a multivariate framework enables a more precise extraction of the factor.

\footnotetext{
${ }^{17}$ They follow the NBER chronology closely, for example.

${ }^{18}$ Again, we use the startup values shown in the first column of Table 2.
} 


\section{Concluding Remarks}

We have argued that a model with factor structure and regime switching is a useful modern contribution to a long tradition in the analysis of business-cycle data. We proposed a stylized version of such a model and suggested its compatibility with macroeconomic data and macroeconomic theory.

Let us summarize our stance on the importance of the two attributes of the business cycle that we have focused on. It appears to us that comovement among business-cycle indicators is undeniable. This comovement could perhaps be captured by a VAR representation. The factor structure that we have advocated goes further, in that it implies restrictions on the VAR representation, restrictions that could be at odds with the data. Although more research is needed on that issue, the factor model is nothing more than a simple way of empirically implementing the common idea of fewer sources of uncertainty than variables.

The alleged nonlinearity of the business cycle is open to more dispute. The linear model has two key virtues: (1) it works very well much of the time, in economics as in all the sciences, in spite of the fact that there is no compelling a priori reason why it should, and (2) there is only one linear model, in contrast to the many varieties of nonlinearity. Why worry, then, about nonlinearity in general, and regime switching in particular?

First, a long tradition in macroeconomics, culminating with the earlier-discussed theories of strategic complementarities and spillovers in imperfectly competitive environments, thick-market externalities in search, self-fulfilling prophesies, and so on, makes predictions that seem to accord with the regime-switching idea.

Second, regime-switching models seem to provide a good fit to aggregate output data. Our rejections of the no-switching null hypothesis, in particular, are very strong.

Third, the cost of ignoring regime switching, if in fact it occurs, may be large. Business people, for example, want to have the best assessments of current and likely future 
economic activity, and they are particularly concerned with turning points. Even tiny forecast improvements that may arise from recognizing regime switching may lead to large differences in profits. ${ }^{19}$ Similarly, for policy makers, if regime switching corresponds to movements between Pareto-rankable equilibria, there are important policy implications. ${ }^{20}$ Finally, macroeconomists, more generally, are interested in a host of issues impinged upon by the existence or non-existence of regime switching. Optimal decision rules for consumption and investment (including inventory investment), for example, may switch with regime, as may agents' ability to borrow.

There are many directions for future research. For example, we are pursuing the possibility of constructing and maximizing the exact likelihood function, which is straightforward conceptually but has been computationally infeasible thus far. The multimove Gibbs sampler, in conjunction with a partially non-Gaussian state space representation and a simulated EM algorithm, as developed recently by Shephard (1994) and de Jong and Shephard (1993), may provide the key.

${ }^{19}$ For an example of forecast improvements from a model with regime switching see Huh (1993).

${ }^{20}$ Moreover, countercyclical policy may itself introduce nonlinearities if it is applied only in extreme situations. See Zarnowitz and Moore (1982) and Becketti and Haltiwanger (1987). 


\section{References}

Andrews, D.W.K. (1993), "Tests for parameter instability and structural change with unknown change point," Econometrica, forthcoming.

Azariadis, C. (1981), "Self-Fulfilling Prophesies," Journal of Economic Theory, 25, 380-396.

Backus, D.K. and Kehoe, P.J. (1992), "International Evidence on the Historical Properties of Business Cycles," American Economic Review, 82, 864-888.

Becketti, S. and Haltiwanger, J. (1987), "Limited Countercyclical Policies," Journal of Public Economics, 34, 311-328.

Bollerslev, T., R.F. Engle, and J.M. Wooldridge (1988), "A Capital Asset Pricing Model with Time Varying Covariances," Journal of Political Economy, 95, 116-131.

Bums, A.F. and Mitchell, W.C. (1946), Measuring Business Cycles. New York: National Bureau of Economic Research.

Caballero, R.J. and Lyons, R.K. (1992), "External Effects in U.S. Procyclical Productivity," Journal of Monetary Economics, 30, 107-128.

Cass, D. and Shell, K. (1983), "Do Sunspots Matter?," Journal of Political Economy, 91, 193227.

Cecchetti, S. G., Lam, P. and Mark, N. C. (1990), "Mean Reversion in Equilibrium Asset Prices," American Economic Review, 80, 398-418.

Cooley, T.F., ed. (1993), Frontiers of Business Cycle Research, forthcoming.

Cooley, T.F. and Hansen, G.D. (1990), "The Inflation Tax in a Real Business Cycle Model," American Economic Review, 79, 733-748.

Cooper, R. (1993), "Equilibrium Selection in Imperfectly Competitive Economies With Multiple Equilibria," manuscript, department of economics, Boston University.

Cooper, R. and John, A. (1988), "Coordinating Coordination Failures in Keynesian Models," Quarterly Journal of Economics, 103, 441-463.

de Jong, P. and N. Shephard (1993), "Efficient Sampling From the Smoothing Density in Time Series Models," Manuscript, Faculty of Commerce and Business Administration, University of British Columbia.

De Toldi, M., C. Gourieroux, and A. Monfort (1992), "On Seasonal Effects in Duration Models," Working Paper \#9216, INSEE, Paris.

Diamond, P. (1982), "Aggregate Demand Management in Search Equilibrium," Journal of Political Economy, 90, 881-894.

Diamond, P. and Fudenberg, D. (1989), "Rational Expectations Business Cycles in Search Equilibrium," Journal of Political Economy, 97, 606-19. 
Diebold, F.X. and Chen, C. (1993), "Testing Structural Stability With Endogenous Break Point: A Size Comparison of Analytic and Bootstrap Procedures," Manuscript, Department of Economics, University of Pennsylvania.

Diebold, F.X., Lee, J.-H., and Weinbach, G.C. (1993), "Regime Switching with Time-Varying Transition Probabilities," in C. Hargreaves (ed.), Nonstationary Time Series Analysis and Cointegration (Advanced Texts in Econometrics, C.W.J. Granger and G. Mizon, eds.). Oxford: Oxford University Press, forthcoming.

Diebold, F.X. and Nerlove, M. (1989), "The Dynamics of Exchange Rate Volatility: A Multivariate Latent-Factor ARCH Model," Journal of Applied Econometrics, 4, 1-22.

Diebold, F.X. and Rudebusch, G.D. (1989), "Scoring the Leading Indicators," Journal of Business, 64, 369-392.

Diebold, F.X., and Rudebusch, G.D. (1990), "A Nonparametric Investigation of Duration Dependence in the American Business Cycle," Journal of Political Economy, 98. 596-616.

Diebold, F.X. and Rudebusch, G.D. (1992), "Have Postwar Economic Fluctuations Been Stabilized?," American Economic Review, 82, 993-1005, 1992.

Diebold, F.X., G.D. Rudebusch, and D. Sichel (1993), "Further Evidence on Business Cycle Duration Dependence," in J.H. Stock and M.W. Watson (eds.), Business Cycles, Indicators and Forecasting, 255-284. Chicago: University of Chicago Press for NBER.

Durland, J.M. and McCurdy, T.H. (1992), "Modelling Duration Dependence in Cyclical Data Using a Restricted Semi-Markov Process," Manuscript, Department of Economics, Queen's University.

Durlauf, S.N. (1991), "Multiple Equilibria and Persistence in Aggregate Fluctuations," American Economic Review, 81 (May), 70-74.

Durlauf, S. N. (1994), "An Incomplete Markets Theory of Business Cycle Fluctuations," in C. Hargreaves (ed.), Nonstationary Time Series Analysis and Cointegration (Advanced Texts in Econometrics, C.W.J. Granger and G. Mizon, eds.). Oxford: Oxford University Press, forthcoming.

Engel, C. and J.D. Hamilton (1990), "Long Swings in the Dollar: Are They in the Data and do Markets Know It?" American Economic Review, 80, 4, 689-713.

Engle, R.F. and Granger, C.W.J. (1987), "Co-Integration and Error Correction: Representation, Estimation and Testing," Econometrica, 55, 251-276.

Engle, R.F. and Kozicki,S. (1993), "Testing for Common Features," Journal of Business and Economic Statistics, forthcoming.

Evans, G. and Honkapohja, S. (1993), "Increasing Social Returns, Learning and Bifurcation Phenomena," in A. Kirman and M. Salmon (eds.), Learning and Rationality in Economics. Oxford: Basil Blackwell. 
Filardo, A.J. (1993), "Business Cycle Phases and Their Transitions," Manuscript, Research Department, Federal Reserve Bank of Kansas City.

Garcia, R. (1992), "Asymptotic Null Distribution of the Likelihood Ratio Test in Markov Switching Models," Manuscript, Department of Economics, University of Montreal.

Gene, E. and Zinn, J. (1990), "Bootstrapping General Empirical Measures," Annals of Probability, 18, 851-869.

Geweke, J. (1977), "The Dynamic Factor Analysis of Economic Time Series Models," in D.J. Aigner and A.S. Goldberger (eds.), Latent Variables in Socioeconomic Models. Amsterdam: North-Holland.

Ghysels, E. (1993a), "On the Periodic Structure of the Business Cycle," Journal of Business and Economic Statistics, forthcoming.

Ghysels, E. (1993b), "A Time Series Model with Periodic Stochastic Regime Switching," Discussion Paper \#84, Institute for Empirical Macroeconomics.

Goldfeld, S.M. and R.E. Quandt (1973), "A Markov Model for Switching Regressions," Journal of Econometrics, 1, 3-16.

Green, G.R. and B.A. Beckman (1992), "The Composite Index of Coincident Indicators and Alternative Coincident Indexes," Survey of Current Business, 72, 42-45.

Hall, R.E. (1989), "Temporal Agglomeration," Working Paper \#3143, National Bureau of Economic Research, Cambridge, Massachusetts.

Hamilton, J.D. (1988), "Rational-Expectations Econometric Analysis of Changes in Regime: An Investigation of the Term Structure of Interest Rates, "Journal of Economic Dynamics and Control, 12, 385-423.

Hamilton, J.D. (1989), "A New Approach to the Economic Analysis of Nonstationary Time Series and the Business Cycle," Econometrica, 57, 357-384.

Hamilton, J.D. (1990), "Analysis of Time Series Subject to Changes in Regime," Journal of Econometrics, $45,39-70$.

Hamilton, J.D. (1993), "State-Space Models," in R. Engle and D. McFadden (eds.), Handbook of Econometrics, Volume 4. Amsterdam: North-Holland, forthcoming.

Hamilton, J.D. and Susmel, R. (1992), "Autoregressive Conditional Heteroskedasticity and Changes in Regime," Manuscript, Department of Economics, University of California, San Diego.

Hansen, B.E. (1991), "Inference When a Nuisance Parameter is not Identified Under the Null Hypothesis," Manuscript, Department of Economics, University of Rochester.

Hansen, B.E. (1992), "The Likelihood Ratio Test Under Non-Standard Conditions: Testing the Markov Trend Model of GNP," Journal of Applied Econometrics, 7, S61-S82. 
Hansen, G.D. (1985), "Indivisible Labor and the Business Cycle," Journal of Monetary Economics, 16, 309-327.

Hansen, L.P. and Sargent, T.J. (1993), Recursive Linear Models of Dynamic Economies. Princeton: Princeton University Press.

Howit, P. and P. McAfee (1992), "Animal Spirits," American Economic Review, 82, 493-507.

Huh, C.G. (1993), "Forecasting Industrial Production Using Models with Business Cycle Asymmetry," Manuscript, Research Department, Federal Reserve Bank of San Francisco.

Kydland, F.E. and Prescott, E.C. (1982), "Time to Build and Aggregate Fluctuations," Econometrica, 50, 1345-1371.

Lucas, R.E. (1976), "Understanding Business Cycles," in K. Brunner and A. Meltzer (eds), Stabilization of the Domestic and International Economy (Carnegie-Rochester Series on Public Policy, 5, 7-29.) Amsterdam: North-Holland.

Neftci, S.N. (1984), "Are Economic Time Series Asymmetric Over the Business Cycle?," Journal of Political Economy, 92, 307-328.

Potter, S.M. (1992), "A Nonlinear Approach to U.S. GNP," Manuscript, Department of Economics, University of Califormia, Los Angeles.

Quah, D. and Sargent, T.J. (1993), "A Dynamic Index Model for Large Cross Sections," in J.H. Stock and M.W. Watson (eds.), Business Cycles, Indicators and Forecasting, 285 310. Chicago: University of Chicago Press for NBER.

Quandt, R.E. (1958), "The Estimation of Parameters of Linear Regression System Obeying Two Separate Regimes," Journal of the American Statistical Association, 55, 873-880.

Sargent, T.J. (1987), Macroeconomic Theory, 2nd edition. Boston: Academic Press.

Sargent, T.J. (1989), "Two Models of Measurements and the Investment Accelerator," Journal of Political Economy, 97, 251-287.

Sargent, T.J. and Sims, C. (1977), "Business Cycle Modeling Without Pretending to Have Too Much a Priori Theory," in C. Sims (ed.), New Methods of Business Cycle Research. Minneapolis: Federal.Reserve Bank of Minneapolis.

Shephard, N. (1994), "Partial Non-Gaussian State Space," Biometrika, forthcoming.

Shishkin, J. (1961), Signals of Recession and Recovery, NBER Occasional Paper \#77. New York: NBER.

Sichel, D.E. (1992), "Inventories and the Three Phases of the Business Cycle," Manuscript, Economic Activity Section, Federal Reserve Board.

Sims, C.A. (1980), "Macroeconomics and Reality," Econometrica, 48, 1-48. 
Singleton, K. (1980), "A Latent Time Series Model of the Cyclical Behavior of Interest Rates," International Economic Review, 21, 559-575.

Stinchcombe, M.B. and White, H. (1993), "Consistent Specification Testing With Unidentified Nuisance Parameters Using Duality and Banach Space Limit Theory," Discussion Paper 93-14, Department of Economics, University of California, San Diego.

Stock, J.H., and Watson, M.W. (1989), "New Indexes of Coincident and Leading Economic Indicators," in O. Blanchard and S. Fischer (eds.), NBER Macroeconomics Annual, 1989. Cambridge, Mass.: MIT Press.

Stock, J.H. and Watson, M.W. (1991), "A Probability Model of the Coincident Economic Indicators," in K. Lahiri and G.H. Moore (eds.), Leading Economic Indicators: New Approaches and Forecasting Records. Cambridge: Cambridge University Press.

Stock, J.H. and Watson, M.W. (1993), "A Procedure for Predicting Recessions with Leading Indicators: Econometric Issues and Recent Experience," in J.H. Stock and M.W. Watson (eds.), Business Cycles, Indicators and Forecasting, 255-284. Chicago: University of Chicago Press for NBER.

Tinbergen, J. (1939), Statistical Testing of Business Cycle Theories, Volume II: Business Cycles in the United States of America, 1919-1932. Geneva: League of Nations.

Tong, H. (1983), Threshold Models in Non-linear Time Series Analysis. New York: Springer-Verlag.

Watson, M.W. and Engle, R.F. (1983), "Alternative Algorithms for the Estimation of Dynamic Factor, Mimic and Varying Coefficient Models," Journal of Econometrics, $15,385-400$.

Zarnowitz, V. and Moore, G.H. (1982), "Sequential Signals of Recession and Recovery," Journal of Business, 55, 57-85. 
Table 1

Data Description

\section{Composite Indexes of Coincident Indicators, Alternative Methodologies}

CCI: Composite Index of Four Coincident Indicators, Commerce Department Methodology, $1982=100$

CCIM: Experimental Composite Index of Four Coincident Indicators, Modified Commerce Department Methodology, $1982=100$

CCISW: Experimental Composite Index of Four Coincident Indicators, Stock-Watson Methodology, August $1982=100$

\section{Components of the Composite Index of Four Coincident Indicators}

Commerce Department Methodology (CCI) and

Modified Commerce Department Methodology (CCIM)

PILTP: Personal Income Less Transfer Payments, Seasonally Adjusted at an Annual Rate, Trillions of 1987 Dollars

MIP: Index of Industrial Production, Seasonally Adjusted, $1987=100$

MTS: Manufacturing and Trade Sales, Seasonally Adjusted at an Annual Rate, Millions of 1982 Dollars

ENAP: Employees on Non-Agricultural Payrolls, Seasonally Adjusted at an Annual Rate, Millions of People

Components of the Composite Index of Four Coincident Indicators Stock-Watson Methodology (CCISW)

Same as CCI, except Employees on Nonagricultural Payrolls (ENAP) is replaced by:

HENAP: Hours of Employees on Nonagricultural Payrolls, Seasonally Adjusted at an Annual Rate, Billions of Hours 
Table 2

Estimated AR(1) Markov-Switching Models

\begin{tabular}{|c|c|c|c|c|c|c|}
\hline & START & CCIM & PILTP & ENAP & IP & MTS \\
\hline$\mu_{0}$ & -0.50 & $\begin{array}{l}-0.91 \\
(0.17)\end{array}$ & $\begin{array}{l}-0.75 \\
(0.45)\end{array}$ & $\begin{array}{c}-0.54 \\
(0.13)\end{array}$ & $\begin{array}{l}-4.12 \\
(0.70)\end{array}$ & $\begin{array}{l}-2.26 \\
(0.96)\end{array}$ \\
\hline$\mu_{1}$ & 0.50 & $\begin{array}{l}0.97 \\
(0.11)\end{array}$ & $\begin{array}{l}0.88 \\
(0.15)\end{array}$ & $\begin{array}{l}0.61 \\
(0.09)\end{array}$ & $\begin{array}{l}1.16 \\
(0.29)\end{array}$ & $\begin{array}{l}1.01 \\
(0.27)\end{array}$ \\
\hline$\rho_{1}$ & 0.40 & $\begin{array}{l}0.66 \\
(0.10)\end{array}$ & $\begin{array}{l}0.35 \\
(0.10)\end{array}$ & $\begin{array}{l}0.97 \\
(0.08)\end{array}$ & $\begin{array}{l}0.52 \\
(0.09)\end{array}$ & $\begin{array}{l}0.38 \\
(0.11)\end{array}$ \\
\hline$\sigma^{2}$ & 0.80 & $\begin{array}{l}0.31 \\
(0.04)\end{array}$ & $\begin{array}{l}0.48 \\
(0.08)\end{array}$ & $\begin{array}{l}0.10 \\
(0.01)\end{array}$ & $\begin{array}{l}2.04 \\
(0.24)\end{array}$ & $\begin{array}{l}2.13 \\
(0.38)\end{array}$ \\
\hline $\mathrm{p}_{\infty}$ & 0.75 & $\begin{array}{l}0.70 \\
(0.10)\end{array}$ & $\begin{array}{l}0.68 \\
(0.16)\end{array}$ & $\begin{array}{l}0.63 \\
(0.11)\end{array}$ & $\begin{array}{l}0.57 \\
(0.15)\end{array}$ & $\begin{array}{l}0.45 \\
(0.28)\end{array}$ \\
\hline$p_{11}$ & 0.90 & $\begin{array}{l}0.92 \\
(0.02)\end{array}$ & $\begin{array}{l}0.96 \\
(0.03)\end{array}$ & $\begin{array}{l}0.95 \\
(0.02)\end{array}$ & $\begin{array}{l}0.96 \\
(0.02)\end{array}$ & $\begin{array}{l}0.95 \\
(0.04)\end{array}$ \\
\hline LR & -- & $37.41 * * *$ & $25.16 * * *$ & $35.35^{* * *}$ & $116.33^{* * *}$ & $73.19 * * *$ \\
\hline
\end{tabular}

Notes to table: The column labeled "START" contains the startup values used for iteration. The other column labels denote the variable (defined in Table 1) to which the Markov-switching model is fitted. Asymptotic standard errors appear in parentheses. The sample period is 1952 .I - 1993.I. LR is the likelihood-ratio statistic for the null hypothesis of a one-state model against the alternative of a two-state model; ${ }^{* *}$ denotes significance at the $1 \%$ level using the Garcia (1992) critical values. 
Figure 1

Transition Probability Matrix

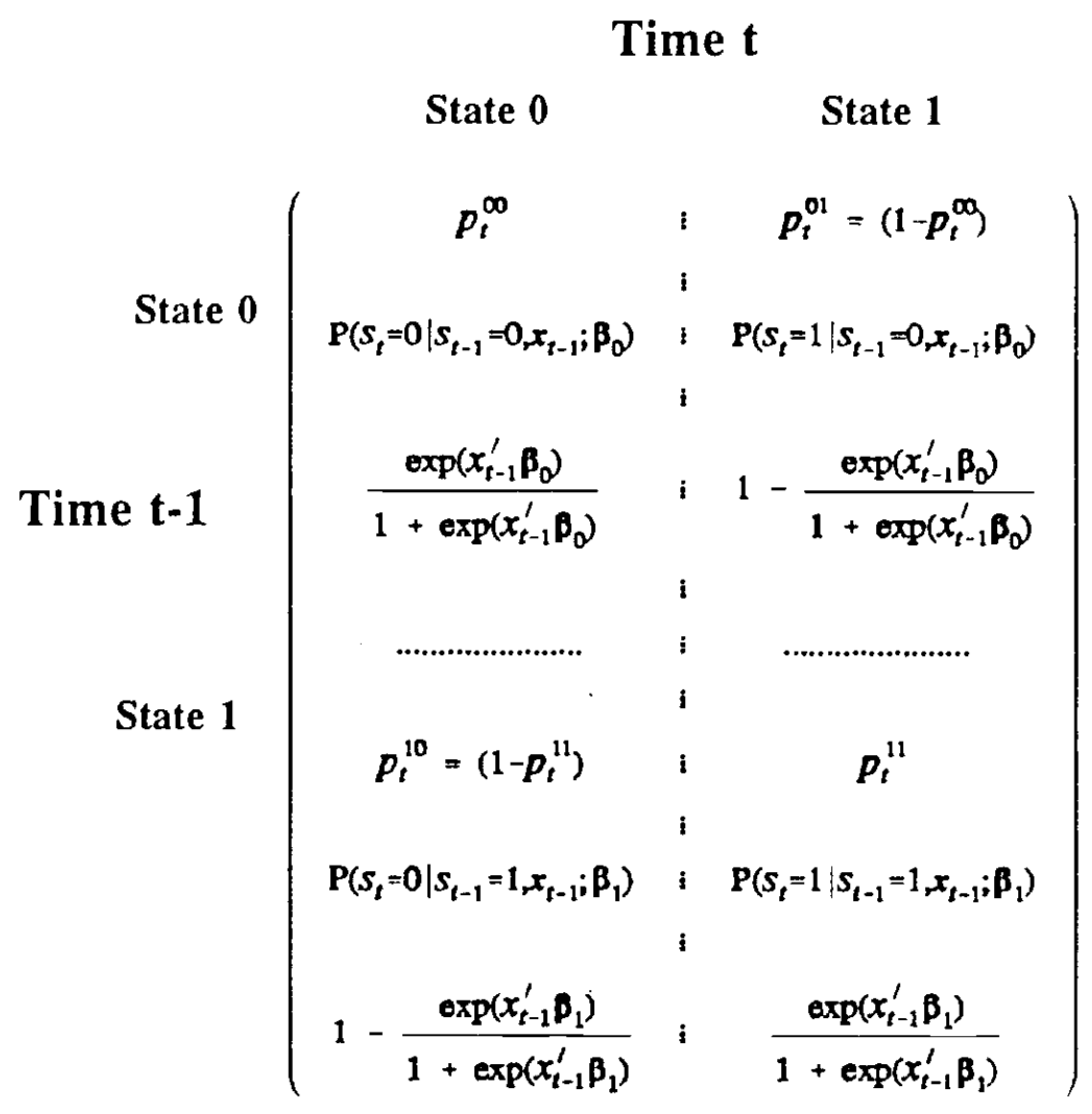

Note to figure: $x_{t-1}=\left(1, x_{1, t-1}, \ldots, x_{(k-1), t-1}\right)^{\prime}$ and $\beta_{i}=\left(\beta_{10,} \beta_{i l}, \ldots, \beta_{t(k-1)}\right)^{\prime}, \mathrm{i}=0,1$ 
Figure 2

Log of Composite Coincident Index

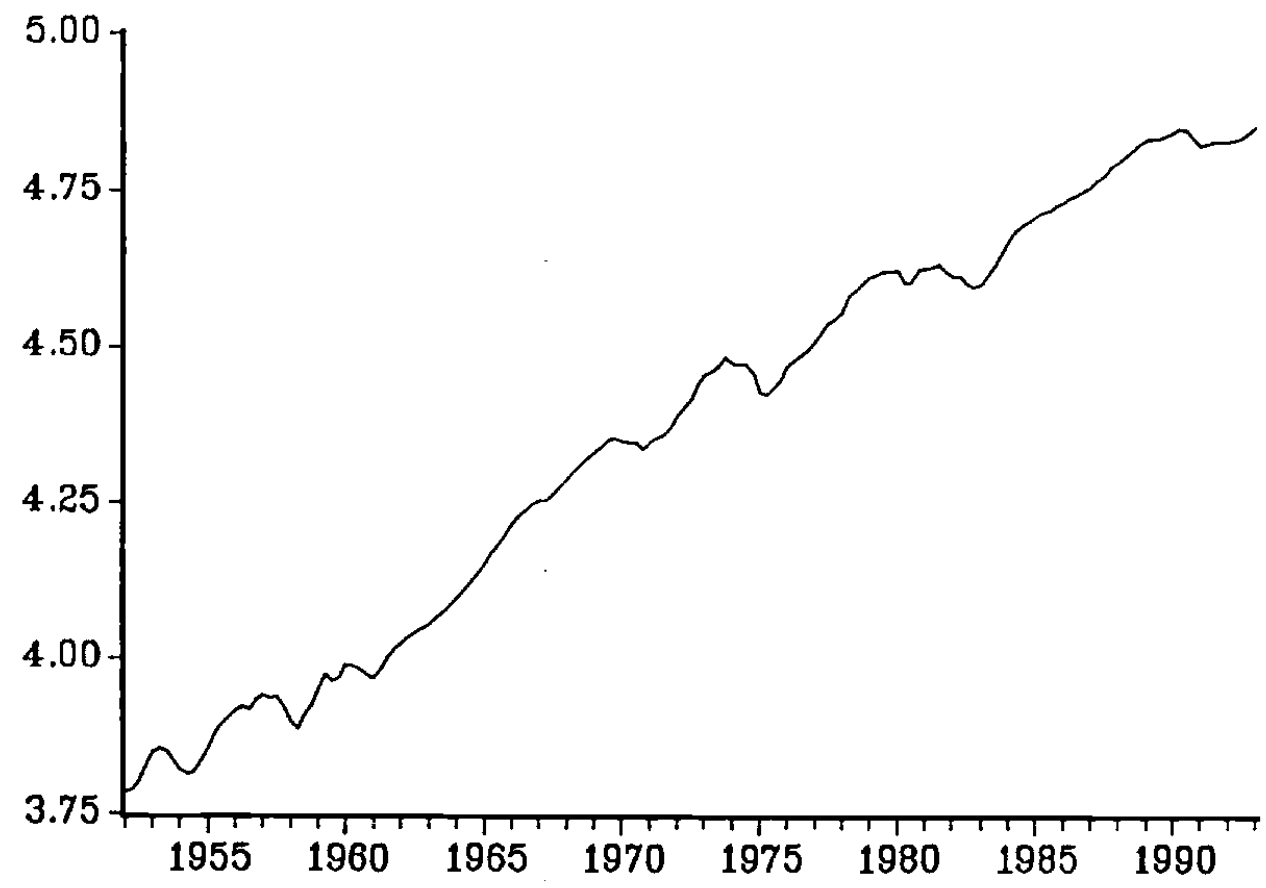


Figure 3

\section{Logs of Coincident Indicators}

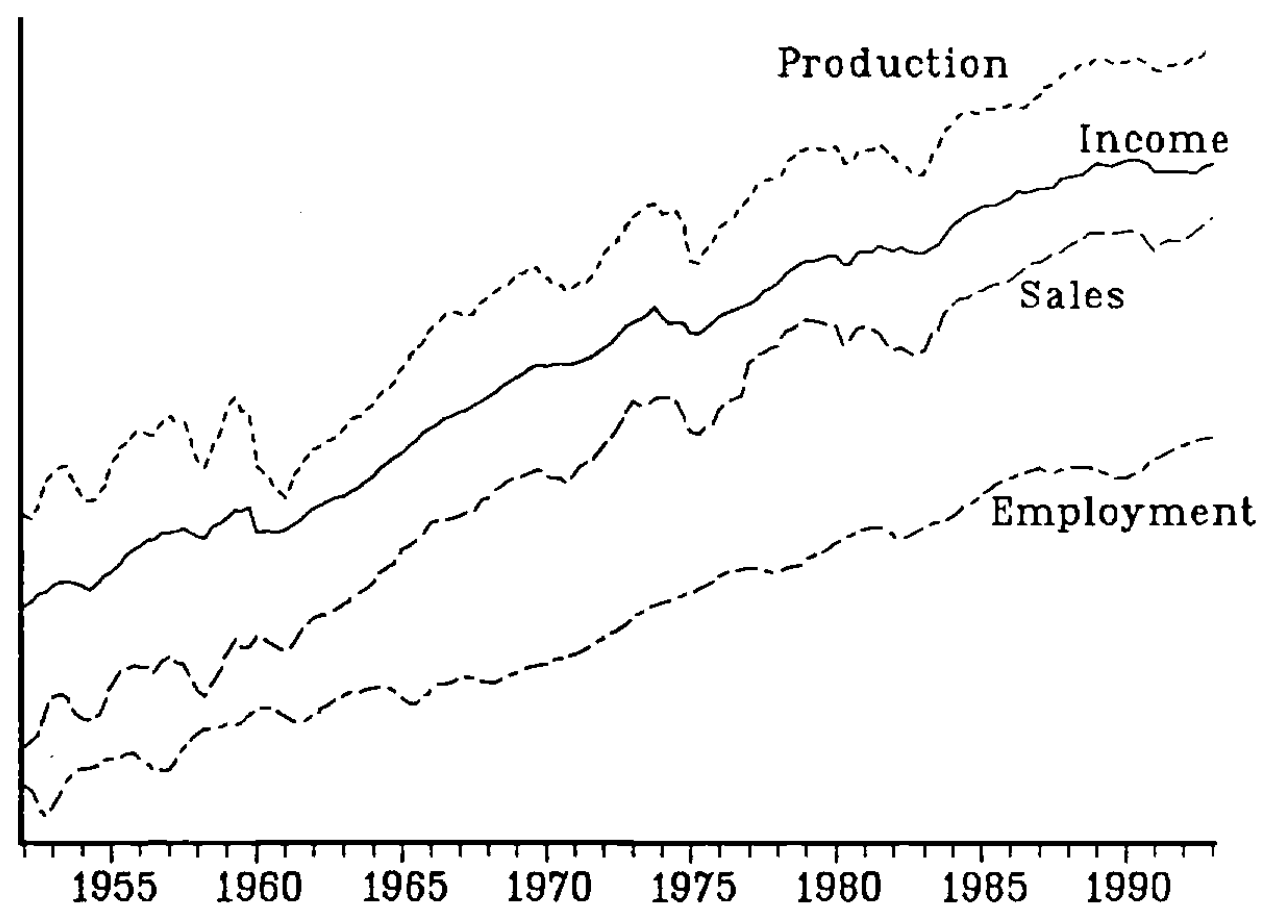


Figure 4

Smoothed Probabilities of Being in State 0 Composite Coincident Index

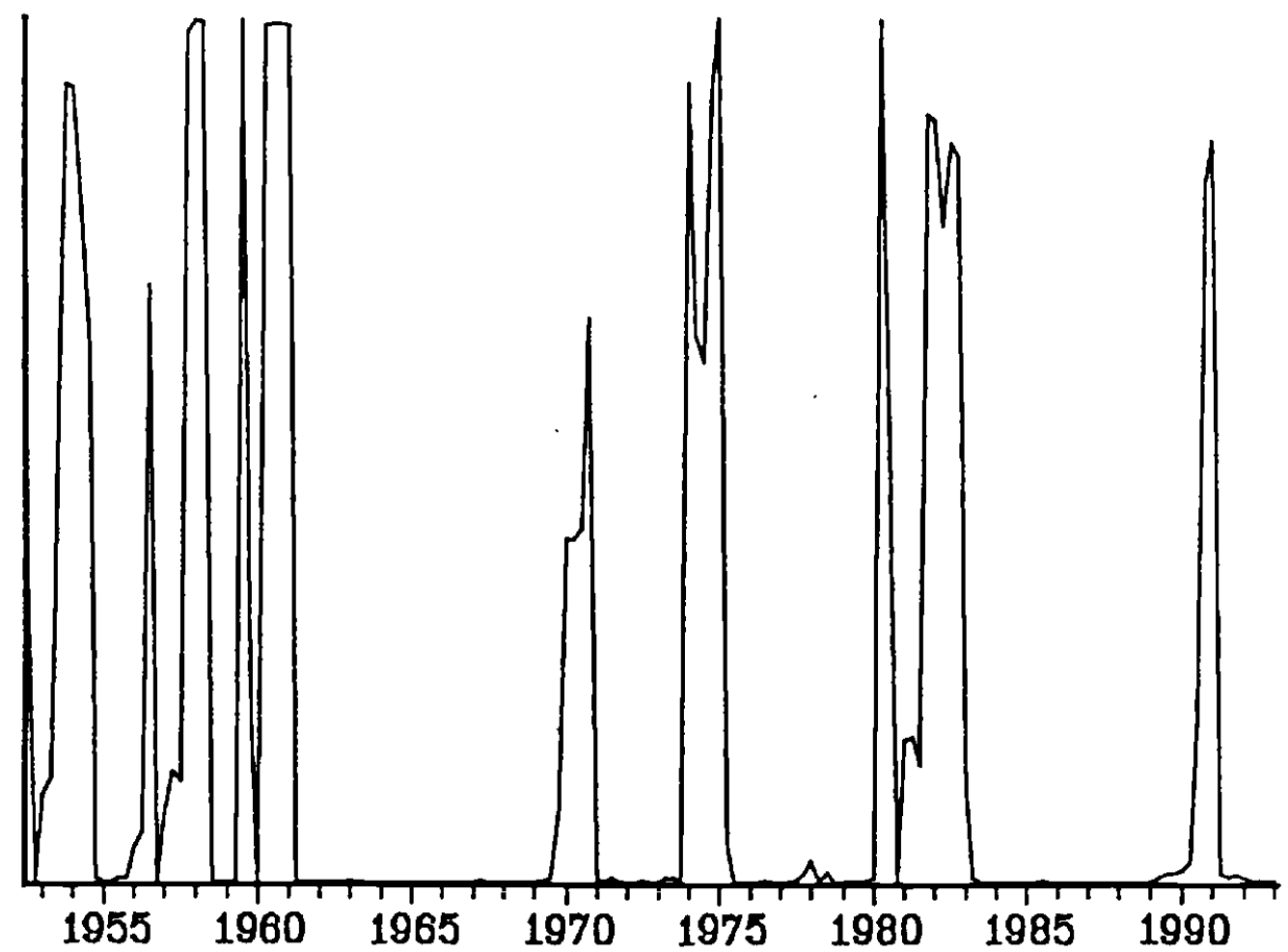


Figure 5

Smoothed Probabilities of Being in State 0 Coincident Indicators
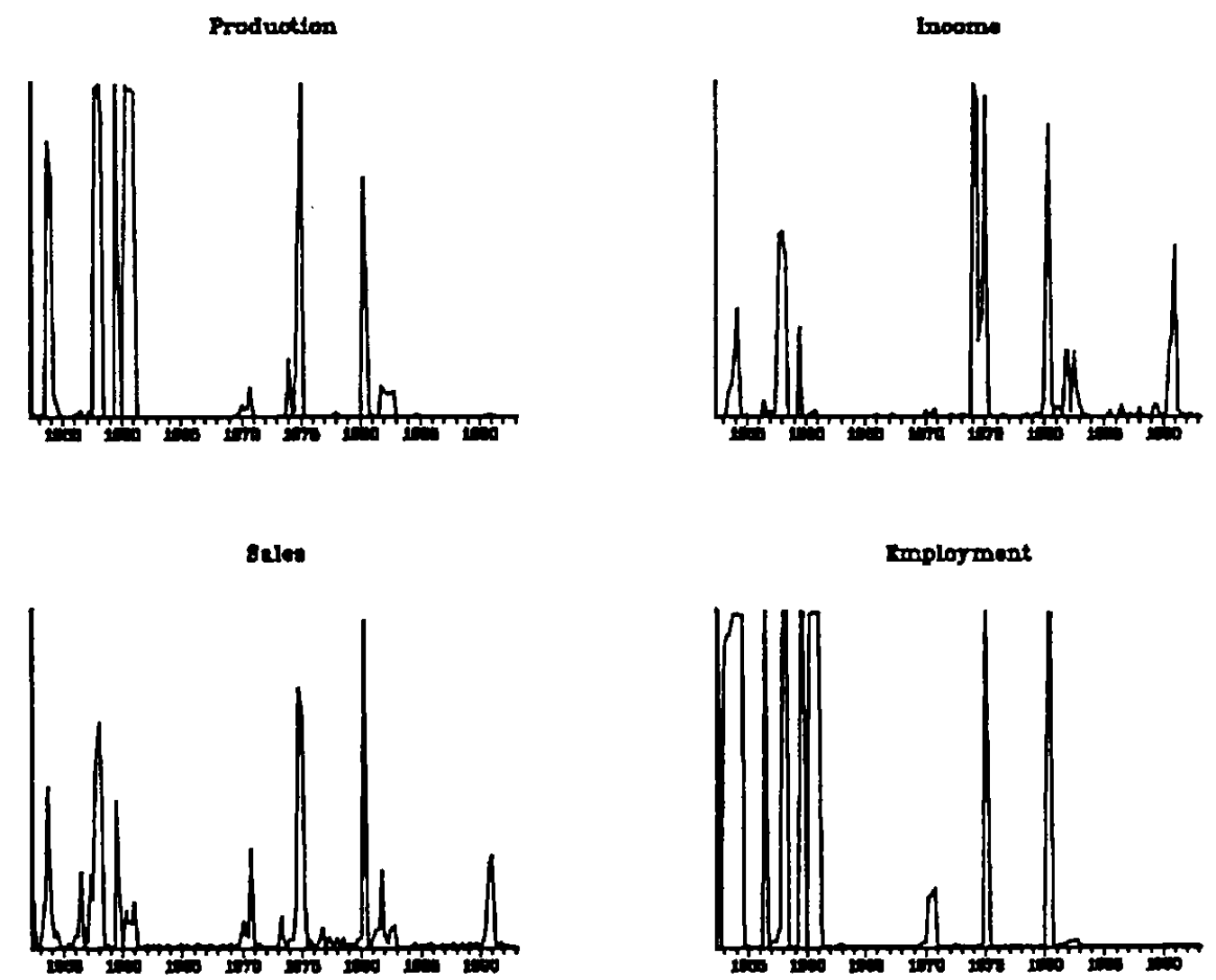